\title{
HORIZONTAL EVOLUTION OF INTERMITTENT GAS- LIQUID FLOWS WITH HIGHLY VISCOUS PHASES
}

\author{
J. HERNANDEZ, J. C. MONTIEL, A. PALACIO-PEREZ, A. RODRÍGUEZ-VALDÉS \& J. E. V. GUZMÁN \\ Universidad Nacional Autónoma de México, Instituto de Ingeniería, México.
}

\begin{abstract}
Experimental work on high viscosity two-phase flows is presented. Newtonian mixtures were produced by simultaneously injecting Glycerine, with dynamic viscosity of $1.2 \mathrm{~Pa} . \mathrm{s}(1,200 \mathrm{cP})$, and air. Then, the analysed flow developed in a horizontal pipe with a length-to-diameter ratio $\mathrm{L} / \mathrm{d}=500$. Various combinations of gas and liquid flow rates were considered within the respective ranges 1.66 $\left(1.66 \times 10^{-3} \leq q_{g} \leq 3.33 \times 10^{-3}\right) \mathrm{m}^{3} / \mathrm{s}$, and $\left(0.125 \times 10^{-3} \leq q_{l} \leq 0.785 \times 10^{-3}\right) \mathrm{m}^{3} / \mathrm{s}$. The experiments show that only intermittent flow patterns can be produced with the flow rates under consideration. Furthermore, a preliminary comparison with some well-known correlations suggests that the typical methods could yield inadequate predictions of the flow properties. Therefore, an alternative analysis based on the spectral content of the pressures is considered. This method allows for a proper characterization of a given flow in terms of its unique spectral 'footprint', which globally condenses all aspects of the underlying dynamics.
\end{abstract}

Keywords: gas, high viscosity, horizontal, Intermittent, liquid

\section{INTRODUCTION}

Intermittent gas-liquid flow patterns can be defined as a sequence of liquid slugs and gas bubbles. Depending on the relative amounts of gas and liquid, the flow may be further classified as slug and plug flow. Such flows represent one of the most complex two-phase flow regimes, since the liquid is not uniformly organized in the axial direction. This leads to an intrinsically unsteady flow condition. In the pure slug flow pattern (typically formed in horizontal pipes), the entire cross-section is occupied by a mass of liquid of a certain length. This liquid slug is followed by a stratified region where an elongated gas bubble flows above a slower liquid layer. Notwithstanding, from the dynamical point of view, other patterns of the intermittent class produce much less clear pressure signals than the slug flow. It is important to acknowledge that all these cases are quite relevant in several industrial processes. Particularly, the oil and gas, the geothermal, and the nuclear industries provide many illustrative examples involving liquid-gas flows.

Because of their social and economic relevance, intermittent flows have been extensively investigated both from the experimental and theoretical points of view. It is important to emphasize that most studies have focused especially on the low viscosity flows (e.g. Weisman [1], Taitel [2]). Air and water have been the primary substances with which the experimental work has been conducted. Nonetheless, the interest on highly viscous two-phase flows has grown in recent times in the context of the oil industry [3-6]. This is primarily due to the actual increment of unconventional crude oil production around the world. In certain oil producing regions, the viscosities of the crudes actually produced may be as high as $100 \mathrm{~Pa}$.s (e.g. Pemex [7]). Despite the obvious need for extensive research on this kind of problems, the number of publications dealing with mixtures where the liquid phase has a dynamic viscosity in excess of 1 Pa.s (Baba, 2017) is still very limited. In turn, this limits the possibility of evaluating and further developing new correlations. 
As a result, the present work is aimed at obtaining experimental data on the pressure drops caused by mixtures where the liquid phases have such high viscosities. Initially, the flow under investigation is horizontal. A comparison among the obtained results and two successful correlations (i.e. the Lockhart-Martinelli (Chisholm, 1967) and TUFFP Unified Model V2016) will be discussed. In addition, a preliminary analysis based on the pressure measurements will be commented. The analysis is based on a Fourier decomposition of the pressure signals and will eventually be utilized to characterize the experimentally observed intermittent flow patterns.

\section{EXPERIMENTS}

The experimental setup shown in Fig. 1 was built to investigate the flow properties of liquidair mixtures produced with high viscosity liquids. The hydraulic subsystem comprised two fluid storage tanks with a volume capacity of $2.8 \mathrm{~m}^{3}$, in addition to a $1864 \mathrm{~W}$ Seepex progressive cavity pump delivering a liquid flow rate of $5 \times 10^{-3} \mathrm{~m}^{3} / \mathrm{s}$ at a maximum pressure of $5 \times 10^{5} \mathrm{~Pa}$. The fluids of interest were water, glycerine and air. Their respective densities and viscosities were $\rho_{w}=10^{3}$ $\mathrm{kg} / \mathrm{m}^{3}, \rho_{g}=1,260 \mathrm{~kg} / \mathrm{m}^{3}, \rho_{a}=1.2 \mathrm{~kg} / \mathrm{m}^{3}, \mu_{w}=1 \times 10^{-3}$ Pa.s, $\mu_{g}=1.2$ Pa.s, and $\mu_{a}=1.8 \times 10^{-5}$ Pa.s.

Compressed air was stored in a $2 \mathrm{~m}^{3}$ container, kept at a constant pressure of $7 \times 10^{6} \mathrm{~Pa}$. A regulator enabled a fine tuned air injection into the test section. The flow rate was measured with a flow rotameter, whose resolution was $8.3 \times 10^{-4} \mathrm{~m}^{3} / \mathrm{s}$.

The fully configurable test section was $38 \mathrm{~m}$ long, with transparent PVC sections with an internal diameter of $0.0762 \mathrm{~m}$. A fully horizontal layout was implemented. The work fluids were injected at the inlet of the test section through a Y connection tube. The pressures were sampled at $1000 \mathrm{~Hz}$ by Honeywell gauge pressure transducers of the series FP2000. Their associated resolution error was less than $0.01 \%$ across a measuring range that spanned from $0.0 \mathrm{~Pa}$ to $1.1 \times 10^{5} \mathrm{~Pa}$. These pressure transducers were located along the pipeline with an $11 \mathrm{~m}$ separation between them. The corresponding current output was channelled to a National Instruments SCXI-1000 data acquisition system. Subsequent signal post-processing was performed with Matlab®.

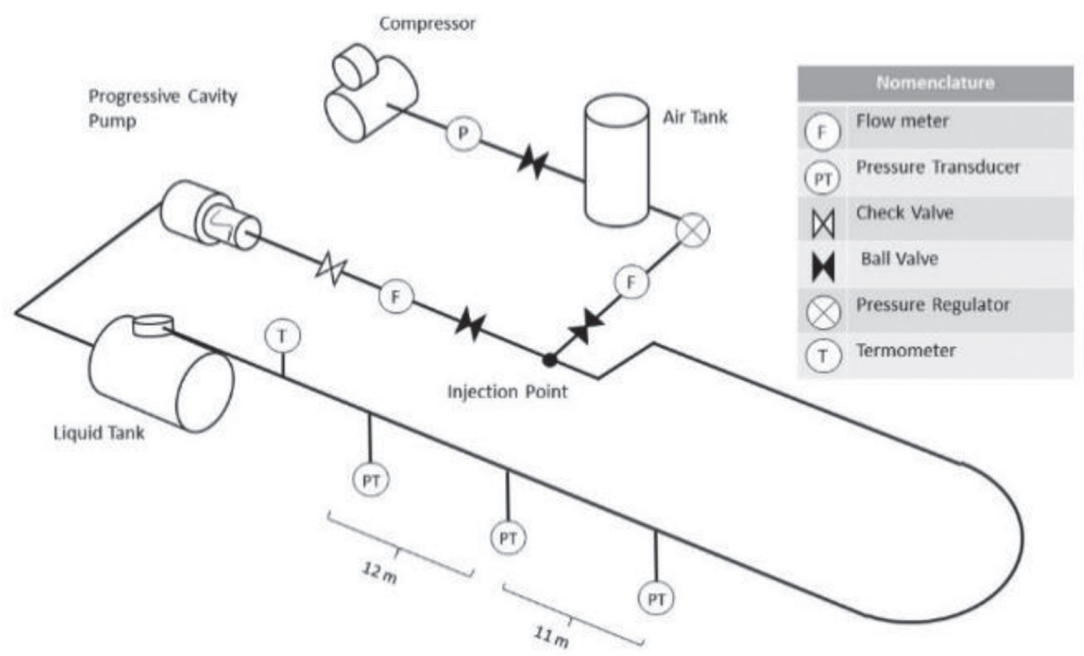

Figure 1: Experimental setup. The schematic shows the configuration of the test loop, as well as the location of the injection port and the transducers. 
Table 1: Experimental flow rates for the water and air mixtures.

\begin{tabular}{lllll}
\hline $\boldsymbol{q}_{g} \times 10^{-3} \mathrm{~m}^{3} / \mathrm{s}$ & \multicolumn{2}{l}{$\boldsymbol{q}_{l} \times 10^{-3} \mathrm{~m}^{3} / \mathrm{s}$} & & \\
\cline { 2 - 5 } & $\mathbf{1 . 5 7}$ & $\mathbf{2 . 7 3}$ & $\mathbf{3 . 8 4}$ & $\mathbf{4 . 9 7}$ \\
\hline $\mathbf{1 . 6 6}$ & $1 \mathrm{a}$ & $1 \mathrm{~b}$ & $1 \mathrm{c}$ & $1 \mathrm{~d}$ \\
$\mathbf{3 . 3 3}$ & $2 \mathrm{a}$ & $2 \mathrm{~b}$ & $2 \mathrm{c}$ & $2 \mathrm{~d}$ \\
$\mathbf{4 . 1 6}$ & $3 \mathrm{a}$ & $3 \mathrm{~b}$ & $3 \mathrm{c}$ & $3 \mathrm{~d}$ \\
$\mathbf{5 . 8 3}$ & $4 \mathrm{a}$ & $4 \mathrm{~b}$ & $4 \mathrm{c}$ & $4 \mathrm{~d}$ \\
$\mathbf{7 . 5}$ & $5 \mathrm{a}$ & $5 \mathrm{~b}$ & $5 \mathrm{c}$ & $5 \mathrm{~d}$ \\
$\mathbf{9 . 1 6}$ & $6 \mathrm{a}$ & $6 \mathrm{~b}$ & $6 \mathrm{c}$ & $6 \mathrm{~d}$ \\
\hline
\end{tabular}

Table 2: Experimental flow rate intervals for the glycerine and air mixtures.

\begin{tabular}{llll}
$\boldsymbol{q}_{g} \times 10^{-3}\left[\frac{\boldsymbol{m}^{3}}{\mathrm{~s}}\right]$ & $\boldsymbol{q}_{l} \times 10^{-3}\left[\frac{\boldsymbol{m}^{3}}{\mathrm{~s}}\right]$ & & \\
\cline { 2 - 4 } & $\mathbf{0 . 1 2 5}$ & $\mathbf{0 . 4 5 5}$ & $\mathbf{0 . 7 8 5}$ \\
\hline $\mathbf{1 . 6 6}$ & $1 \mathrm{ag}$ & $1 \mathrm{bg}$ & $1 \mathrm{cg}$ \\
$\mathbf{2 . 5}$ & $2 \mathrm{ag}$ & $2 \mathrm{bg}$ & $2 \mathrm{cg}$ \\
$\mathbf{3 . 3 3}$ & $3 \mathrm{ag}$ & $3 \mathrm{bg}$ & $3 \mathrm{cg}$ \\
\hline
\end{tabular}

Tables 1 and 2 summarize the experimental flow rate intervals for the water-air mixture and the glycerine-air mixture, respectively.

The experiments were always initiated with the lowest possible volume flow rates of both phases. Then, the liquid flow rate was kept constant, while the air flow rate was increased progressively to each of the values reported in the tables. After a series was completed, the system was restarted, and the liquid flow rate was increased to the next value of interest. The air was injected again starting from the lowest possible flow rate. This procedure was followed for all the series indicated in Tables 1 and 2. Besides the pressure measurements, video recording of the flow was also carried out to evaluate the slugs' velocities, and the liquid holdups (these results are not reported in this paper).

\section{RESULTS AND ANALYSIS}

\subsection{Two-phase pressure response}

The experimental results indicate that only intermittent flow patterns emerge, when mixtures with viscosities in excess of $\mu \sim 1$ Pa.s are involved. Particularly, under normal operating conditions, the stratified and wavy flows patterns were not observed. This is due to the fact that, regardless of how small the inlet flow rates are, the in situ liquid holdup grows very quickly owing to the extremely low mobility of the liquid.

In addition, the two-phase flow pressure response differs quite significantly when low and high viscosity mixtures are considered. Figure 2 shows the pressure plots for water-air and 


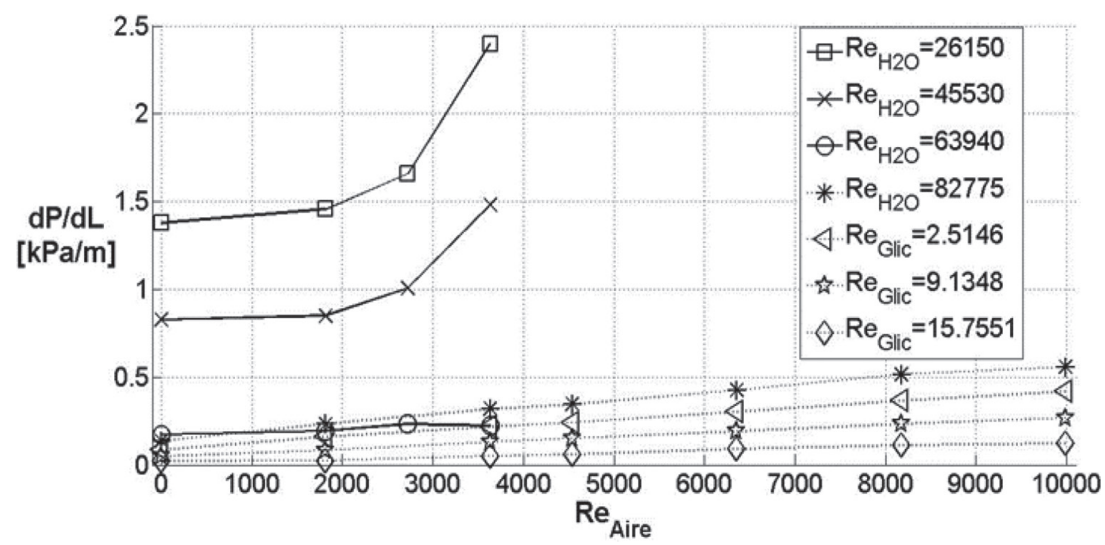

Figure 2: Two phase pressure drops for water and glycerine.

glycerine-air mixtures. The observed discrepancies suggest that the gaseous phase is the main responsible for such an outcome.

The pressure gradient $d p / d x$ is plotted in terms of the Reynolds number for the air, $R e_{a}=4 \rho_{a} q_{a} / \pi \mu_{a} d$. Meanwhile, each curve corresponds to different Reynolds numbers for the water $R e_{w}=4 \rho_{w} q_{w} / \pi \mu_{w} d$, and for the glycerine $R e_{g}=4 \rho_{g} q_{g} / \pi \mu_{g} d$. Apparently, the water-air mixture produces a total pressure gradient, $\Delta p / L$, which is almost linear within the range of air flow rates considered in the study. A direct comparison with the values predicted by, for example, the Lockhart-Martinelli correlation,

$$
\Delta p(f(\mu), u)=\varphi^{2}(X(\mu, u)) f \frac{L}{d} \frac{\rho u^{2}}{2}=\text { const. } * \varphi^{2} f u^{2}
$$

indeed confirms the validity of the usual methods with low viscosity mixtures. However, this robust type of correlation fails to correctly predict the pressure drop when highly viscous phases are considered (Fig. 3).

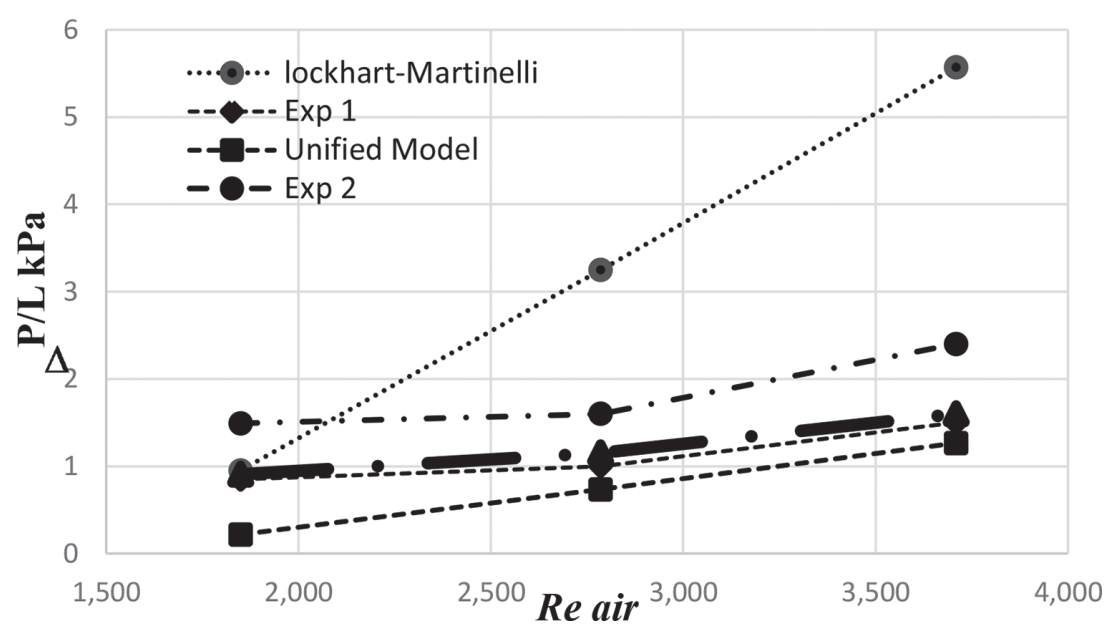

Figure 3: Two-phase pressure drops for water and glycerine. 
Note that the correlation quickly over predicts the actual pressure drop and, furthermore, it is unable to reflect the non-linear behaviour (curve a in Fig. 4). Accordingly, this work in progress is aimed at developing a relationship of the form

$$
\Delta p\left(\mu_{g}, u_{g}, u_{a}\right)=C_{1}+C_{2} \varphi^{n} \mu_{g} u_{m}^{2}
$$

for the pressure drop. Here, the multiplier function $\varphi$, together with its exponent $n$ and the coefficients $C_{1}$ and $C_{2}$, must be determined from the pressure signals. To this end, it is assumed that the pressure response related with the each type of intermittency may be fully characterized by its unique spectral footprint. In other words, a Fourier decomposition would convey the detailed information required to reinterpret equation 2 in terms of an expansion. Although it is not yet based on this approach, this trial equation yields the dashed curve shown in Fig. 4 for the reported results.

Figures 4 and 5 provide a closer look at the development of the pressures for both kinds of mixtures. The snapshots are arranged from left to right for increasing gas flow rates, and from top to bottom for increasing liquid flow rates. Each curve in the snapshots is in correspondence with one of the three pressure transducers located along the test section.

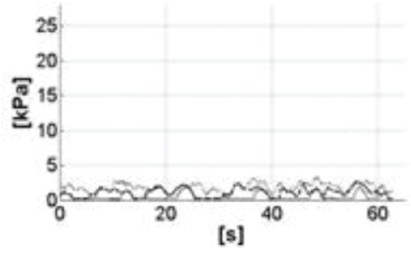

a)

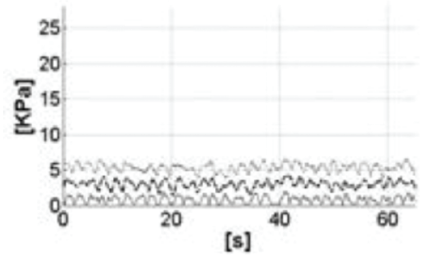

c)

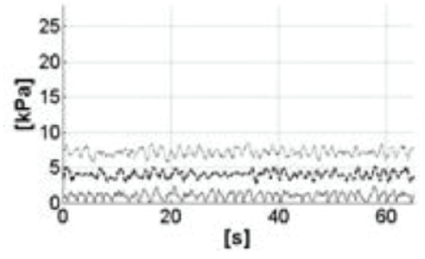

e)

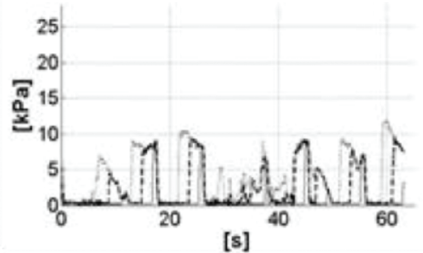

b)

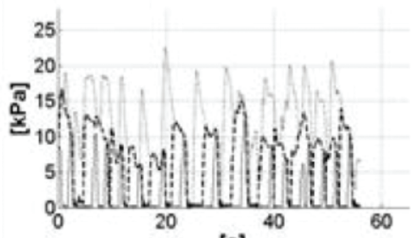

[s]

d)

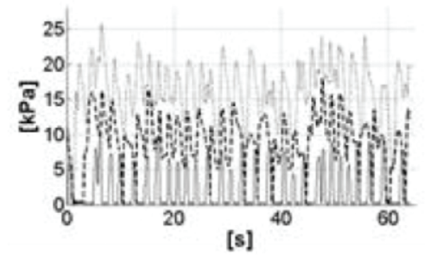

f)

Figure 4: Two-phase pressure drop for water-air mixtures. The gas flow rates increases from left to right, and the liquid flow rate increases from top to bottom. 


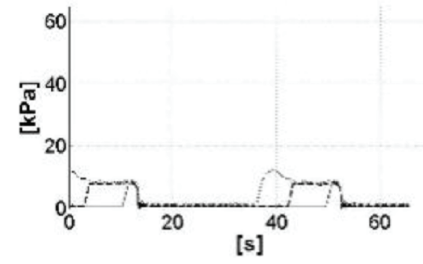

a)

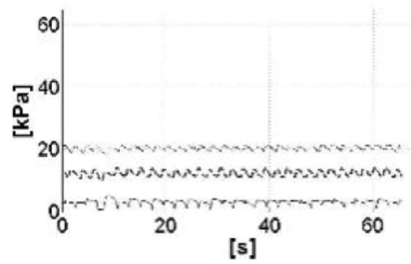

c)

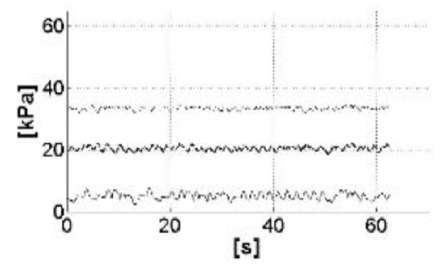

e)

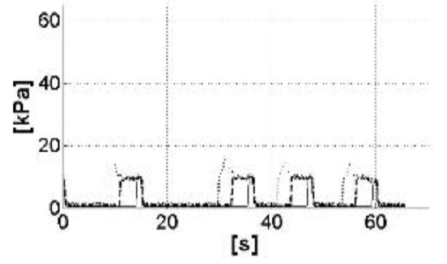

b)

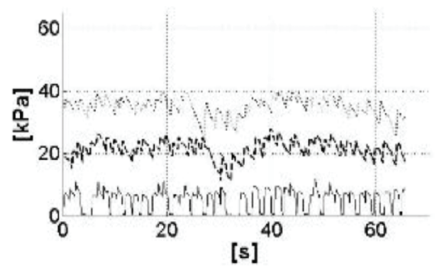

d)

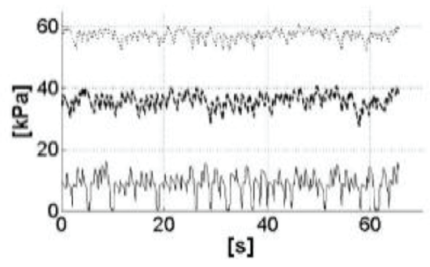

f)

Figure 5: Two-phase pressure drop for glycerine-air mixtures. The gas flow rates increases from left to right, and the liquid flow rate increases from top to bottom.

In the particular case of water-air mixtures, the flow for low $q_{w}$ and $q_{a}$ is characterized by a plug pattern with elongated bubbles (Fig. 4a). At higher $q_{w}$, the bubbles become smaller (Figs. $4 \mathrm{c} \&$ e); the corresponding pressures increase by a factor of order one. However, the flow develops in a drastically different manner when $q_{a}$ is increased. A true slug flow results for moderate $q_{w}$ and higher gas flow rates (Fig. 4b). It is important in this case to note that the pressure levels increase considerably. With intermediate to high $q_{w}$ and $q_{a}$, the slug units shorten somewhat, but the pressure peaks attain are quite significant (Fig. 4d). In the severest case depicted by Fig. 4f, a succession of short but fast moving slugs is produced. Furthermore, the pressure peaks generated inside the tube are two to three times higher, than with low $q_{a}$ for the same $q_{w}$.

The situation is slightly different for flows with glycerine-air mixtures. If the inlet flow rates $q_{g}$ and $q_{a}$ are low, the flow pattern is essentially a plug flow with small bubbles. This explains the irregular pressure fluctuations observed in Fig. 5a. Higher $q_{g}$ once more implies the production of smaller bubbles (Figs. $5 \mathrm{c}$ and e). This is due to the fact that the flow drags the bubbles, elongating them, and breaking them up into smaller units. If on the other hand, the air flow rate $q_{a}$ is increased, small slugs are formed (Figs. $5 \mathrm{~b}, \mathrm{~d} \&$ e). The respective pressures in each one of these cases increases accordingly. It is interesting to note, however, that the pressure levels do not increase substantially with respect to the baseline case (i.e. Fig. 5a). Such behaviour is to be expected, because the high viscosity phase is the one mainly contributing to the pressure drop. 


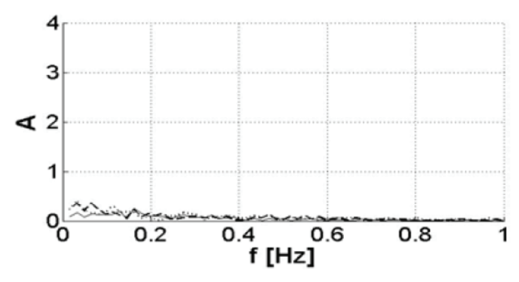

a)

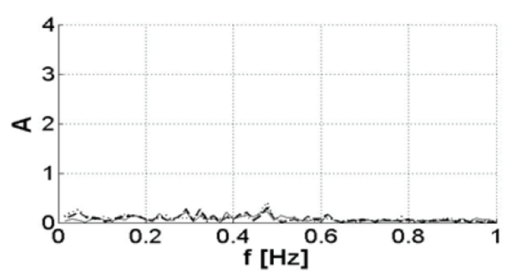

c)

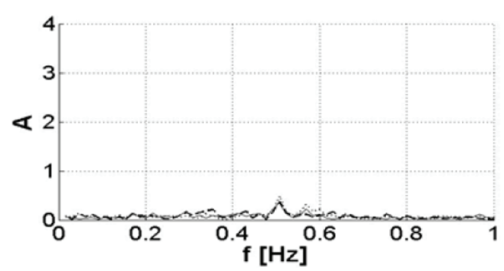

e)

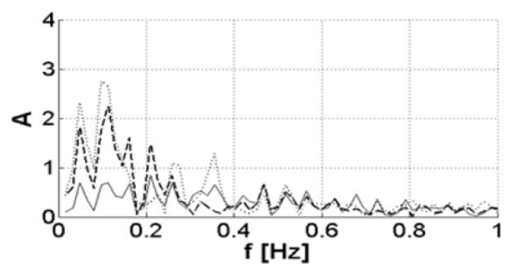

b)

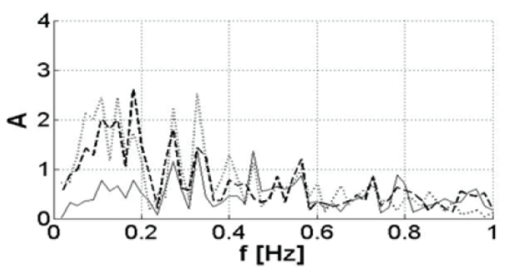

d)

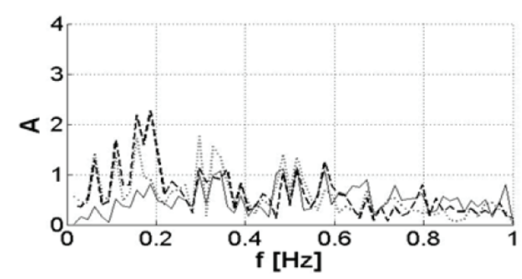

f)

Figure 6: Frequencies patterns for water-air intermittent flows.

\subsection{Characteristic frequencies}

The frequency-based characterization presented here does not refer to the slug formation frequency. Rather, these spectral footprints convey information on the internal pressures and its fluctuations. Figures 6 and 7 correspond to the mixtures under consideration and are organized in the same fashion described above. The amplitudes are normalized in terms of the respective average pressures.

For comparison purposes, the flow of water-air mixtures is considered first. The frequency content corresponding to the low end of the flow rate intervals indicates that the small amplitude contributions are distributed in the 0.3 to $0.4 \mathrm{~Hz}$ band (Fig. 6a). Interestingly, as the liquid flow rate is increased, the waves' components contributing more to the pressure level tend to group at around $0.5 \mathrm{~Hz}$ (Fig. 6c). When the maximum water flow rate $\left(q_{w}\right)$ is attained, the dominant component seen in Fig. 6e appears at $5 \mathrm{~Hz}$. This means, in other words, that the pressure in the system may be expected to fluctuate at that specific frequency for those given values of $q_{w}$ and $q_{a}$. In contrast, the effect associated with the flow of air is different. As the air flow rates are increased, the respective frequency bands tend to expand. Thus, for low $q_{w}$ and high $q_{a}$, the upper frequency limit moves from approximately $0.4 \mathrm{~Hz}$ to nearly $0.8 \mathrm{~Hz}$ (higher frequency components contribute little to the pressure build up). This situation is depicted by Fig. 6b. Of greater relevance is the fact that the high amplitude components lay 
mostly in the $0.4 \mathrm{~Hz}$ band. Near the upper end of the air flow rate interval, the pressure components spread over a wide range of frequencies, a situation clearly seen in Figs. $7 \mathrm{~d}$ and $\mathrm{f}$.

Next, turning our attention to the glycerine-air flow cases illustrated in Fig. 6, we notice some similarities and some differences. At the lower end of both flow rate intervals, the relevant pressure components strongly dominate the low-frequency band of the spectrum (Fig. 7a). With somewhat higher $q_{g}$, most of the components gather about a strong peak, whose approximate frequency is $0.43 \mathrm{~Hz}$. Interestingly, the number excited modes grow drastically with the highest liquid flow rate. As a matter of fact, it can be shown that two of the three most important harmonics have frequencies located around $0.6 \mathrm{~Hz}$.

The situation with air is contrasting. Higher air flow rates lead to a significant increase of the fluctuation amplitudes (Figs. 7b, d and f). To a certain extent, the effect is analogous to the one previously described for water-air mixtures. However, since the mean pressure in this

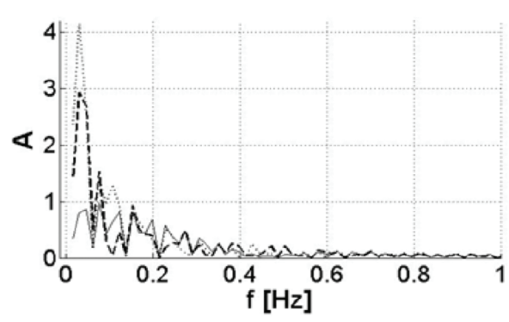

a)

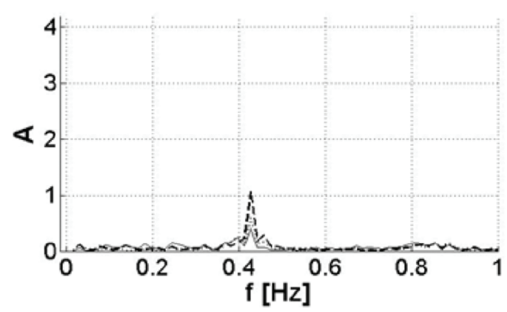

c)

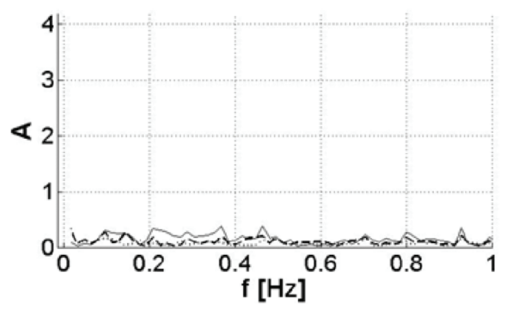

e)

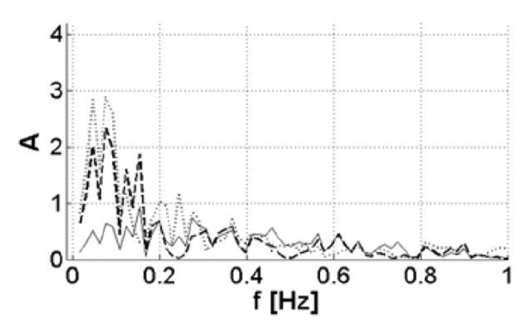

b)

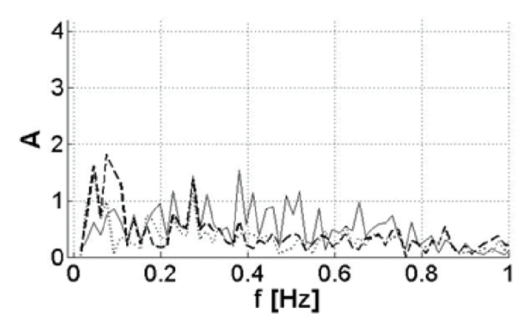

d)

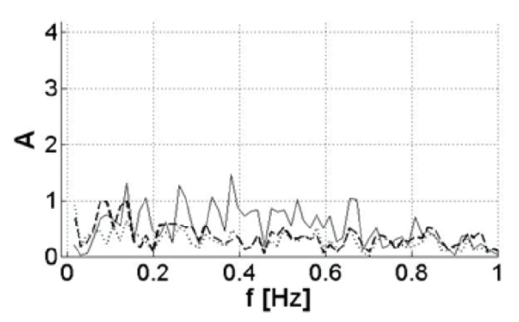

f)

Figure 7: Frequencies patterns for glycerine-air intermittent flows. 


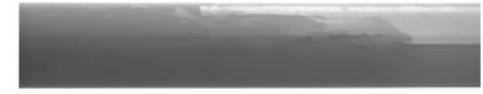

a) $V_{s g}=0.73 \mathrm{~m} / \mathrm{s} \quad V_{s l}=0.03 \mathrm{~m} /$

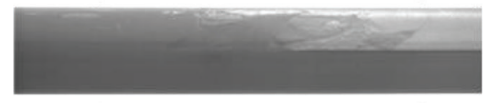

b) $V_{s g}=0.73 \mathrm{~m} / \mathrm{s} \quad V_{s t}=0.1 \mathrm{~m} / \mathrm{s}$

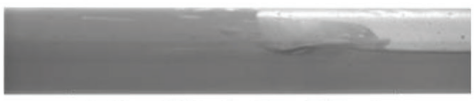

c) $V_{s g}=1.10 \mathrm{~m} / \mathrm{s} \quad V_{s l}=0.17 \mathrm{~m} / \mathrm{s}$

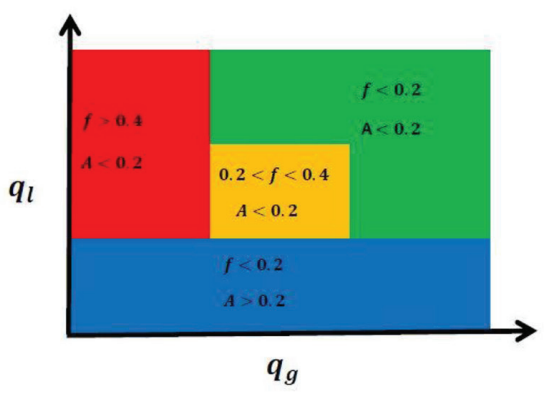

Figure 8: Two-phase mixing fronts for glycerine-air mixtures (left). The gas flow rates increases from left to right, and the liquid flow rate increases from top to bottom.

case is much higher, the peak pressure values have a relatively small effect. It is also noticed that the frequency band extends beyond $1 \mathrm{~Hz}$ in these cases. The peaks obtained with low $q_{g}$ and high $q_{a}$, are mostly congregated around frequencies below $0.2 \mathrm{~Hz}$. The intermediate case shown in Fig. 7d produces lower amplitudes levels distributed over a widely spread frequency band. Once again, in the limit of high $q_{a}$, a greater number of pressure modes is excited; despite the similitude with the previous case, the frequencies of the dominant modes remain below the $0.3 \mathrm{~Hz}$ band.

One possible reason behind the larger number of pressure modes excited at high air flow rates is the severe penetration of the compressed air (contained in the trailing bubbles) into the body of the slugs. Fig. 8 suggests that such penetrations may even reach the mixing front in those cases where the slugs are not too long. Further experimental work is required to establish the nature of such effects. Furthermore, maps as the one shown in Fig. 8(b) can also be elaborated to efficiently convey the relevant information.

\section{CONCLUDING REMARKS}

Experiments with low and high viscosity two-phase mixtures were conducted in a horizontal tube with $L / d=500$ (the internal diameter being $d=0.0762 \mathrm{~m}$ ). The low and high viscosity liquids considered in the study were water $\left(10^{-3} \mathrm{~Pa} . \mathrm{s}\right)$ and glycerine (1.2 Pa.s), respectively. Air constituted the gaseous phase.

Only intermittent flow patterns were observed with the high viscosity mixture. Even when the pipeline was started with a thin layer of viscous fluid, the transition to the intermittent pattern was immediately produced. As a result, a systematic approach based on the analysis of the frequencies was initiated. The aim of the analysis is to reveal the nature of the pressure response in the tube. This entails considering the mean pressure and its fluctuation amplitudes, in terms of their respective frequencies.

The frequency analysis indeed shows that each kind of intermittent flow is characterized by a well-defined set of frequencies and amplitudes. It is then conjectured that these properties can be used to furnish a Fourier representation for the pressures caused by given pairs of liquid and gas inflow rates (assumed to be known or measurable). Future work will prove or dismiss this hypothesis.

Based on the given laboratory measurements, a first attempt to modify a robust correlation (such as Lockhart-Marinelli's correlation) is presented. Its plot suggests that a reasonable agreement with the experimental results may result in some cases. 


\section{ACKNOWLEDGEMENTS}

This work was financially supported by CONACYT.

\section{REFERENCES}

[1] Weisman, J., Effects of fluid properties and pipe diameter on two-phase flow patterns in horizontal lines. International Journal of Multiphase Flow, 5(6), pp. 437-462, 1979. https://doi.org/10.1016/0301-9322(79)90031-4

[2] Taitel, Y., A model for predicting flow regime transitions in horizontal and near horizontal gas-liquid flow. AICHE Journal, 22, pp. 47-55, 1976.

https://doi.org/10.1002/aic.690220105

[3] Al-Safran, E. G. B. a. S., High viscosity liquid effect on two-phase slug length in horizontal pipes, de BHR Group - 15th International Conference on Multiphase Production Technology, 2011.

[4] Al-Safran, E., Kora, C. \& Sarica, C., Prediction of slug liquid holdup in high viscosity liquid and gas two-phase flow in horizontal pipes. Journal of Petroleum Science and Engineering, 133, pp. 566-575, 2015.

https://doi.org/10.1016/j.petrol.2015.06.032

[5] Zhao, Y., Lao, L. \& Yeung, H., Investigation and prediction of slug flow characteristics in highly viscous liquid and gas flows in horizontal pipes. Chemical Engineering Research and Design, 102, pp. 124-137, 2015. https://doi.org/10.1016/j.cherd.2015.06.002

[6] Farsetti, S., Farisè, S. \& Poesio, P., Experimental investigation of high viscosity oil-air intermittent flow. Experimental Thermal and Fluid Science, 57, pp. 285-292, 2014. https://doi.org/10.1016/j.expthermflusci.2013.12.004

[7] PEMEX, Petroleos Mexicanos,17 Enero 2013. [En línea], available at: http:// www.pemex.com/acerca/informes_publicaciones/Paginas/default.aspx

[8] Baba, Y.D., Archibong, A.E., Aliyu, A.M. \& Ameen, A.I., Slug frequency in high viscosity oil-gas two-phase flow: experiment and prediction. Flow Measurement and Instrumentation, 54, pp. 109-123, 2017. https://doi.org/10.1016/j.flowmeasinst.2017.01.002

[9] Chisholm, D., A theoretical basis for the Lockhart-Martinelli correlation for two-phase flow. International Journal of Heat and Mass Transfer, 10, pp. 1767-1778, 1967. https://doi.org/10.1016/0017-9310(67)90047-6

[10] Gokcal, B., Al-Sarkhi, A., Sarica, C. \& Al-safran, E.M., Prediction of slug frequency for high-viscosity oils in horizontal pipes. SPE Projects, Facilities and Construction, 5, pp. 136-144, 2010. https://doi.org/10.2118/124057-pa

[11] Nossen, J. a. L. C., Pressure drop in laminar slug flow with heavy oil. de BHR Group 8th North American Conference on Multiphase Technology 2012, 2012. 